\section{Características dos candidatos à esterilização cirúrgica e os fatores associados ao tipo de procedimento}

\author{
Characteristics of candidates for surgical \\ sterilization and factors associated \\ with type of procedure
}

\author{
Elisabeth Meloni Vieira 1 \\ Suzi Volpato Fábio 2 \\ Wagner Gueleri 2 \\ Miriam Pinheiro Picado 3 \\ Elizabeth Yoshinaga ${ }^{3}$ \\ Luiz de Souza 1
}

\section{Introdução}

Em outubro de 1999, o Sistema Único de Saúde (SUS) de Ribeirão Preto, São Paulo, Brasil, municipalizado em gestão plena, iniciou a oferta da esterilização cirúrgica, conforme a Lei $n$. 9.263 (Diário Oficial da União 1996; 12 jan), que regulamenta o planejamento familiar, previsto no parágrafo 7o do artigo 226 da Constituição Federal. Desde 1988, no Brasil, o planejamento familiar é um direito do cidadão e é definido como um conjunto de ações de regulação da fertilidade, que objetiva garantir direitos iguais de constituição (limitação ou aumento de prole) pela mulher, pelo homem ou pelo casal. Deve ser parte integrante do atendimento à saúde, com ações preventivas e educativas no acesso igualitário às informações e meios de anticoncepção cientificamente aceitos. É dever do Estado assegurar o livre exercício do planejamento familiar, que está instituído no SUS através da Portaria n. 144 do Ministério da Saúde (Diário Oficial da União 1997; 20 nov).

Embora esteja claro na Constituição Federal de 1988 que o Estado deva oferecer o planejamento familiar, o serviço não foi ofertado pelo SUS até 1997, em virtude da ausência de regulamentação e também por causa da ambigüidade sobre a legalidade da esterilização cirúrgica. Nesse período, os Conselhos de Medicina recomendavam a não-realização da cirur- 
gia esterilizadora, pois o médico poderia sofrer conseqüências previstas no Código Penal 1. Contudo, apesar das dúvidas sobre a sua legalidade, a oferta da esterilização, tanto feminina quanto masculina, é uma prática no setor privado ${ }^{2}$. Antes da oferta pelo SUS, as mulheres obtinham a esterilização clandestinamente através do pagamento "por fora”, na hora do parto, freqüentemente por meio de uma cirurgia cesariana ${ }^{3}$. Outras formas de pagamento, como favores políticos em troca da esterilização, foram mencionadas por Caetano ${ }^{4}$. Em Ribeirão Preto, cerca de $60,0 \%$ das mulheres que se esterilizaram em 1998 pagaram pelo procedimento 5 .

Em face das dificuldades de reversão da esterilização, a questão do arrependimento se coloca seriamente, pois atinge de $11,0 \%$ a $15,0 \%$ das mulheres brasileiras esterilizadas 6,7. Como o pagamento atua como um obstáculo ao arrependimento 8 , o seu nível pode ser aumentado após a oferta de esterilização gratuita.

A oferta conjunta dos procedimentos de esterilização, tanto feminina quanto masculina, pelo sistema público, representa uma novidade em termos de serviços de contracepção no Brasil, já que vinham sendo oferecidos por especialistas e eram freqüentemente pagos. Além disso, a esterilização, principalmente a feminina, é bastante prevalente no país. A Pesquisa Nacional de Demografia e Saúde 9 mostrou que, entre as mulheres de 15 a 49 anos sexualmente unidas, $40,1 \%$ estavam esterilizadas, contra apenas $2,6 \%$ dos homens, embora se saiba que este índice representa um aumento significativo da esterilização masculina nos últimos tempos, tanto no Brasil quanto no Estado de São Paulo 10.

Como conseqüência da ausência de serviços que ofertem igualmente a laqueadura e a vasectomia, não há estudos que comparem os casais que escolhem entre um ou outro procedimento e possíveis fatores que possam interferir nessa escolha. Dessa forma, a implantação do programa permitiu a realização deste trabalho.

\section{O programa}

No momento da implantação da oferta dos métodos cirúrgicos, as 31 Unidades Básicas de Saúde (UBS) do município estavam equipadas, oferecendo regularmente métodos anticoncepcionais reversíveis e contando com médicos ginecologistas para o atendimento de contracepção 11. A porta de entrada para a solicitação dos procedimentos cirúrgicos regulamentados pela Lei n. 9.263 (Figura 1) são as unida- des de atenção primária do município. Os requisitos desses procedimentos incluem o aconselhamento por equipe multidisciplinar, que deve desencorajar a esterilização precoce. Estabeleceu-se em uma maternidade local a referência para os dois métodos cirúrgicos, laqueadura por videolaparoscopia e vasectomia, que são realizados por especialistas. O aconselhamento (orientação) oferecido aos candidatos é conduzido por profissionais de saúde treinados e ocorre em um período superior aos sessenta dias, prazo legal mínimo para a cirurgia, após a manifestação da vontade do candidato.

Com o propósito de coletar subsídios para avaliar a oferta de métodos cirúrgicos, desenvolveu-se esta investigação com os seguintes objetivos: (a) caracterizar os candidatos aos métodos cirúrgicos; (b) estudar as variáveis associadas à escolha do tipo de procedimento, laqueadura tubária ou a vasectomia; (c) verificar a adequação à Lei $n .9 .263$ em relação à idade mínima e tempo de espera.

\section{Material e métodos}

O estudo realizou-se por meio do levantamento de 102 prontuários de candidatos aos métodos cirúrgicos. Estes foram encaminhados das UBS para o ambulatório onde se realizava o aconselhamento, entre 4 de novembro de 1999 e 27 de julho de 2000. Escolheu-se esse período por ser o início da implantação, para que os problemas encontrados pudessem ser corrigidos precocemente. O Comitê de Ética em Pesquisa da Faculdade de Medicina de Ribeirão Preto, Universidade de São Paulo aprovou este estudo.

Foram considerados 95 prontuários de casais candidatos, cujos dados foram coletados na primeira entrevista, e que continham também os resumos das sessões de aconselhamento; sete pessoas sem parceiro não fizeram parte da amostra, pois se desejava avaliar os fatores que influenciam a escolha do método cirúrgico pelo casal, e uma pessoa solteira só tinha uma opção. As variáveis selecionadas para estudo foram: idade, sexo, estado marital, escolaridade, religião, renda familiar, número de filhos vivos, motivo da procura do método cirúrgico, uso anterior de contraceptivos, antecedente de aborto, número de orientações recebidas, qualidade do relacionamento conjugal (definido pelo orientador como bom, regular, ruim ou conflituoso com base em informações fornecidas pelos candidatos), o procedimento realizado, o tempo de decisão (contado a partir do registro da primeira data de realização de orientação até a data do procedimento) e a causa do 
não-procedimento. Todos os prontuários foram conferidos com uma lista emitida pela maternidade com nome, data, tipo de procedimento realizado e número de matrícula do usuário no serviço, no período de abril a novembro de 2001. Os dados foram digitados no Epi Info 6.0 e processados pelo Stata 6.0. A análise estatística constou da descrição das variáveis e da procura de fatores que pudessem influenciar na escolha do procedimento cirúrgico (laqueadura ou vasectomia), para a qual foram utilizados os procedimentos de regressão logística e teste exato de Fisher. Considerou-se o nível de significância $\mathrm{p}=0,05$.

\section{Resultados}

\section{Características gerais}

No período analisado houve solicitação de 38 (40,0\%) cirurgias de vasectomia e 57 (60,0\%) de laqueadura. A idade dos candidatos variou de 24 a 59 anos, sendo a idade média 34,2 anos; 57 $(60,0 \%)$ eram casados e $38(40,0 \%)$ viviam em união consensual. Em relação à escolaridade, $51(53,7 \%)$ não tinham o primeiro grau. A renda familiar média mensal calculada foi de $\mathrm{R} \$$ 544,93 , sendo a mínima de $\mathrm{R} \$ 130,00$ e a máxima $\mathrm{R} \$ 1.100,00$ mensais. A renda familiar per capita média mensal calculada foi de $\mathrm{R} \$ 108,81$, sendo a mínima $\mathrm{R} \$ 13,00$ e a máxima, $\mathrm{R} \$ 263,25$. Quatro casais não tinham renda e dependiam de outros para sobreviver. O número médio de membros da família encontrado foi 5,4, variando de 3 a 11 . O número médio de filhos vivos foi 3,3, variando de 1 a 9. Apenas uma candidata tinha um filho. Em relação à religião, a maioria $(62,1 \%)$ identificou-se como católica.

\section{Contracepção}

O uso anterior de anticoncepcional oral foi relatado por $92(96,8 \%)$ candidatos, e $38(40,0 \%)$ referiram o uso do preservativo masculino. Em relação à contracepção atual, 87 (91,6\%) candidatos relataram estar usando algum método, dos quais, $78(89,7 \%)$ utilizavam a pílula. Dos nove candidatos restantes, seis declararam uso de métodos de baixa eficácia (dois usavam a tabela e quatro o coito interrompido). Dezenove mulheres referiram abortos anteriores.

\section{Motivo da procura do método cirúrgico}

Dos candidatos que procuraram os métodos cirúrgicos, $34(35,8 \%)$ o fizeram por estarem satisfeitos com o número de filhos que tinham;
Figura 1

Resumo dos requisitos legais para realização de métodos cirúrgicos de acordo com a Lei n. 9.263.

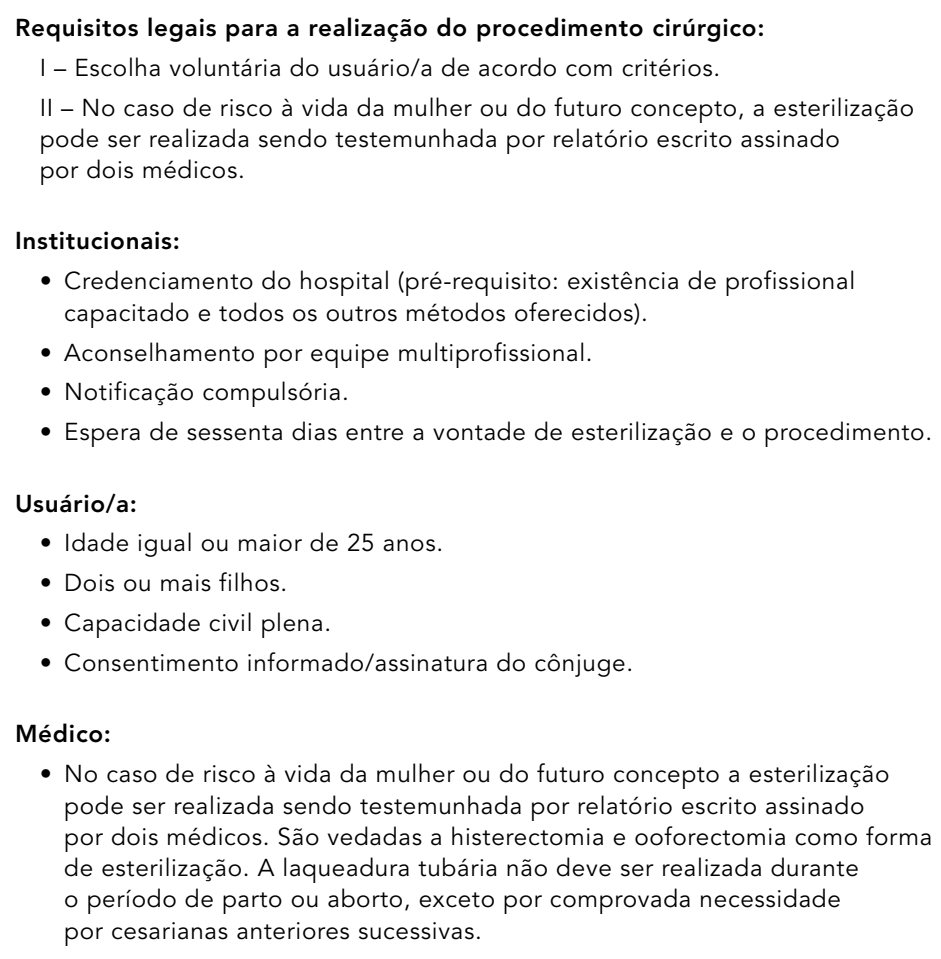

$32(33,7 \%)$, por terem problemas de saúde, inclusive por terem muitas cesáreas anteriores; $16(16,8 \%)$ revelaram não querer mais filhos por dificuldades financeiras e $13(13,7 \%)$ apresentaram outros motivos: consideravam a esterilização o melhor método, apresentavam intolerância a outros procedimentos e tinham filho deficiente.

Dos 95 casais candidatos, $71(74,7 \%)$ referiram ter bom relacionamento conjugal, 19 (20,0\%), relacionamento regular, e 5 (5,3\%), relacionamento ruim.

\section{Aconselhamento}

O tempo médio de aconselhamento foi 201,7 dias. Em apenas um caso houve tempo inferior a sessenta dias entre a solicitação e a realização do procedimento, pois se tratava de caso de risco à saúde previsto em lei. Excluindo-se este, o tempo mais curto entre a manifestação da vontade e o procedimento foi 74 dias, e o mais longo, 438 dias. Realizaram-se, em média, 4,7 sessões de aconselhamento por candidato ou casal, variando de 1 a 9. A maioria participou de 5 (38 candidatos, 40,0\%) ou 6 (21 candi- 
datos, $22,1 \%$ ) sessões de aconselhamento antes de submeter-se à cirurgia. As candidatas que se submeteram à laqueadura receberam maior número de orientações do que os candidatos que se submeteram à vasectomia. Apenas três casais mudaram a opção cirúrgica inicial durante o aconselhamento. Dois casais, que inicialmente haviam optado pela vasectomia, acabaram escolhendo a laqueadura, e com um terceiro casal, aconteceu o inverso.

\section{Procedimentos realizados}

Dos 95 casais que se candidataram à cirurgia esterilizadora, $43(45,3 \%)$ se submeteram à esterilização feminina, $34(35,8 \%)$ à vasectomia e $18(18,9 \%)$ não obtiveram o procedimento (Tabela 1$)$. Treze candidatos $(13,7 \%)$ desistiram do procedimento ou resolveram adiá-lo por motivos diversos: idade jovem, relacionamento conjugal instável, desejo de constituir família em outra união e relacionamento conjugal conflituoso. Os outros cinco candidatos $(5,3 \%)$ haviam obtido a guia para realização da cirurgia, mas não procuraram o hospital de referência no período de dois anos nem foram encontrados por contato telefônico para fornecer mais informações. Três mulheres $(3,2 \%)$ engravidaram, mas apenas uma delas comunicou aos orientadores que durante o processo de aconselhamento havia decidido engravidar novamente.

\section{Associações entre variáveis}

As variáveis idade, escolaridade, estado marital, renda per capita, número de filhos, religião, histórico de aborto e qualidade do relacionamento foram selecionadas como possíveis fatores de influência na decisão do casal para a escolha do método cirúrgico (laqueadura ou vasectomia). Os resultados estão apresentados na Tabela 1.

\section{- Idade}

Nenhum dos candidatos abaixo dos 25 anos foi esterilizado; dos 18 candidatos que não obtiveram o procedimento, $14(77,8 \%)$ tinham menos de 35 anos; das 43 mulheres que se submeteram à laqueadura, $32(74,4 \%)$ tinham menos de 35 anos e, dos 34 homens que se submeteram à vasectomia, $23(67,6 \%)$ tinham 35 anos ou mais.

Encontrou-se a idade média de 37,8 anos para a realização da vasectomia e 32,7 anos para a laqueadura. A vasectomia passa de $25,6 \%$ em homens até 34 anos para $67,6 \%$ em homens com 35 anos ou mais. Portanto, a idade mos- trou ser um fator de influência na escolha do método cirúrgico, no sentido de favorecer a realização de vasectomia em homens de mais idade $(\mathrm{p}<0,001)$. Considerando-se os casais em que um dos parceiros é esterilizado, a chance de vasectomia em homens com mais de 35 anos é 6,1 vezes a chance de vasectomia em homens com menos de 35 anos (OR = 6,1; IC95\%: $2,3-16,4)$.

\section{- Estado marital}

Verificou-se que, entre as mulheres que se submeteram à laqueadura, $48,8 \%$ eram casadas e $51,2 \%$ coabitavam, ao passo que, entre os homens que se submeteram à vasectomia, 79,4\% eram casados e $20,6 \%$ coabitavam. Dentre as pessoas casadas, $56,2 \%$ se submeteram à vasectomia, contra $24,1 \%$ das pessoas que coabitam. O teste de associação resultou em significância ( $\mathrm{p}<0,01)$, o que leva a concluir que os homens casados realizam mais vasectomia do que os que coabitam. Considerando-se os casais em que um dos parceiros é esterilizado, a chance de vasectomia em casados é quatro vezes a chance de vasectomia entre aqueles que apenas coabitam (OR = 4,0; IC95\%: 1,5-12,4).

\section{- Número de filhos}

A porcentagem de mulheres com quatro filhos ou mais que fazem a laqueadura $(73,1 \%)$ é maior que a porcentagem de mulheres com menos de quatro filhos $(47,1 \%)$. O teste mostrou associação significante $(\mathrm{p}=0,03)$ entre procedimento cirúrgico e número de filhos. Mulheres com quatro filhos ou mais fazem mais laqueadura do que mulheres com menos de quatro filhos (OR = 3,1; IC95\%: 1,1-8,5).

As variáveis escolaridade, renda per capita, religião, histórico de aborto e qualidade do relacionamento não se mostraram associadas com o tipo de cirurgia (Tabela 1).

\section{Discussão}

Os resultados mostram que a maioria dos candidatos à esterilização são casais estáveis, de baixa renda e escolaridade, que apresentaram como motivos principais para encerrar a carreira reprodutiva a satisfação com o número de filhos e problemas de saúde; destes, um terço recebeu recomendação médica para não ter outro filho. A maioria já havia tentado limitar a prole fazendo uso de métodos anticoncepcionais reversíveis. A implantação da oferta de métodos cirúrgicos veio atender ao direito consti- 
Distribuição de freqüências e porcentagens dos procedimentos cirúrgicos utilizados segundo alguns fatores, odds ratio (OR) e correspondentes intervalos de 95,0\% de confiança (IC95\%)

\begin{tabular}{|c|c|c|c|c|c|c|c|}
\hline \multirow[t]{3}{*}{ Variável } & \multicolumn{5}{|c|}{ Cirurgia realizada } & \multicolumn{2}{|c|}{ Odds ratio } \\
\hline & \multicolumn{2}{|c|}{ Laqueadura } & \multicolumn{2}{|c|}{ Vasectomia } & \multirow{2}{*}{$\begin{array}{c}\text { Total } \\
\mathrm{N}\end{array}$} & \multirow[t]{2}{*}{ OR } & \multirow[t]{2}{*}{ IC95\% } \\
\hline & $\mathrm{n}$ & $\%$ & $\mathrm{n}$ & $\%$ & & & \\
\hline \multicolumn{8}{|l|}{ Idade (anos)* } \\
\hline Até 34 & 32 & 74,4 & 11 & 25,6 & 43 & 6,1 & $2,3-16,4$ \\
\hline 35 ou mais & 11 & 32,4 & 23 & 67,6 & 34 & & \\
\hline \multicolumn{8}{|l|}{ Escolaridade } \\
\hline Sem o 1ㅇ grau & 23 & 59,0 & 16 & 41 & 39 & 1,3 & $0,5-3,2$ \\
\hline 1ㅇ grau ou mais & 20 & 52,6 & 18 & 47,4 & 38 & & \\
\hline \multicolumn{8}{|l|}{ Estado marital* } \\
\hline Casado & 21 & 43,8 & 27 & 56,2 & 48 & & \\
\hline Coabita & 22 & 75,9 & 7 & 24,1 & 29 & 4,0 & $1,5-12,4$ \\
\hline \multicolumn{8}{|l|}{ Renda per capita } \\
\hline Até $\mathrm{R} \$ 100,00$ & 26 & 60,5 & 17 & 39,5 & 43 & 1,5 & $0,6-3,8$ \\
\hline Mais de $\mathrm{R} \$ 100,00$ & 17 & 50,0 & 17 & 50,0 & 34 & & \\
\hline \multicolumn{8}{|l|}{ Número de filhos ${ }^{\star \star}$} \\
\hline 3 ou menos & 24 & 47,1 & 27 & 52,9 & 51 & & \\
\hline 4 ou mais & 19 & 73,1 & 7 & 26,9 & 26 & 3,1 & $1,1-8,5$ \\
\hline \multicolumn{8}{|l|}{ Religião } \\
\hline Católica & 30 & 57,7 & 22 & 42,3 & 52 & & \\
\hline Outra & 13 & 52,0 & 12 & 48,0 & 25 & 1,3 & $0,5-3,3$ \\
\hline \multicolumn{8}{|l|}{ Histórico de aborto } \\
\hline Não & 33 & 54,1 & 28 & 45,9 & 61 & & \\
\hline Sim & 10 & 62,5 & 6 & 37,5 & 16 & 1,4 & $0,5-4,4$ \\
\hline \multicolumn{8}{|c|}{ Qualidade do relacionamento } \\
\hline Bom ou médio & 39 & 54,2 & 33 & 45,8 & 72 & & \\
\hline Ruim & 4 & 80,0 & 1 & 20,0 & 5 & 3,4 & $0,4-31,7$ \\
\hline
\end{tabular}

$* p<0,01$.

$\star \star p<0,05$.

tucional de limitar o número de filhos, contemplando os indivíduos que têm problemas para tê-los, ou não querem mais reproduzir, bem como aqueles que não poderiam pagar para ter acesso ao procedimento.

A grande porcentagem de escolha da vasectomia mostra que houve mudanças em relação à participação masculina na contracepção, tal como já foi verificado por Duarte et al. 13 em estudo realizado em Campinas, no qual encontrou-se associação entre vasectomia e maior escolaridade e renda. Essas mudanças podem estar relacionadas a atitudes mais liberais em relação aos papéis de gênero, que já foram encontradas em associação com maior escolaridade e melhor condição social 14, o que poderia também falar a favor de mudanças no comportamento masculino sobre seu papel reprodutivo.

A esterilização por vasectomia é pouco freqüente: no Brasil, apenas 2,6\% dos homens se submetem à cirurgia; no Estado de São Paulo, onde a prevalência é maior, o percentual é de $6,1 \%$ dos homens 10 . A grande porcentagem de escolha de vasectomia em Ribeirão Preto está provavelmente relacionada à facilidade da oferta associada ao aconselhamento. Este último permitiria esclarecer os tabus e medos, especialmente aqueles que relacionam a vasectomia com a castração, tal como já foi descrito por alguns autores 15 . 
Chama atenção ter sido a vasectomia encontrada associada à maior idade e ao casamento em detrimento da coabitação. A primeira situação poderia favorecer uma interpretação de adequação da oferta de métodos cirúrgicos, já que a vida reprodutiva masculina é mais longa do que a feminina. Em relação à associação entre vasectomia e casamento, esta sugere um contexto de maior compromisso entre os parceiros.

A oferta dos procedimentos cirúrgicos no Município de Ribeirão Preto está adequada à Lei $n$. 9.263. Verificou-se que nenhum candidato com idade inferior a 25 anos foi esterilizado, e que o tempo que durou o processo de decisão esteve muito além do tempo mínimo de sessenta dias requerido legalmente.

O aconselhamento oferecido está demonstrando eficácia em relação aos objetivos propostos. Verificou-se mudança do procedimento solicitado em apenas três candidatos, mas houve desistência por parte de $13,7 \%$ deles. Talvez esse número fosse maior se os outros cinco candidatos tivessem sido encontrados posteriormente, sendo esta uma das limitações enfrentadas por este estudo. A porcentagem de desistência é compatível com o arrependimento estudado no Brasil 7, o que sugere que o aconselhamento poderia prevenir essa situação, pelo menos em parte.

Este estudo trouxe importantes informações para a melhoria da qualidade da assistência à saúde da mulher, em particular da contracepção. Dez por cento das mulheres encaminhadas da rede básica ao aconselhamento ou não usavam métodos anticoncepcionais ou usavam métodos de baixa eficácia, portanto não foi surpresa a ocorrência de duas gestações não desejadas.

Existe espaço para o aprimoramento da oferta de contracepção reversível, principalmente em nível primário. Outras investigações, com o objetivo de acompanhar a satisfação dos usuários e os candidatos que não retornaram ao programa, podem contribuir fornecendo subsídios para a melhoria deste.
Resumo

Em 1999, a Secretaria Municipal de Ribeirão Preto, São Paulo, Brasil, implantou a oferta de métodos de esterilização cirúrgicos, de acordo com a legislação vigente. Este estudo objetivou caracterizar os candidatos à esterilização cirúrgica e estudar as variáveis associadas ao tipo de procedimento. Foram pesquisados 95 prontuários de candidatos e realizada análise estatística por meio de regressão logística e do teste exato de Fisher, considerando-se o nível de significância de $p=$ 0,05. A maioria dos candidatos são casais estáveis, de baixa escolaridade e baixa renda, satisfeitos com o número de filhos e que já haviam tentado limitar a prole com o uso de anticoncepcionais reversíveis. A média de idade era de 34,2 anos; 45,3\% se submeteram à esterilização feminina; 35,8\%, à vasectomia, e 18,9\% não obtiveram o procedimento. A chance de o homem, com 35 anos ou mais, fazer vasectomia é 6,1 vezes a do homem mais jovem (OR = 6, 1; IC95\%: 2,4-16,4); submetem-se à vasectomia mais homens casados do que os que coabitam $(O R=4,0 ;$ IC95\%: 1,5-12,4) e mulheres com quatro filhos ou mais fazem mais laqueadura do que aquelas com menos de quatro filhos $(O R=3,1$; IC95\%: 1,1-8,5).

Anticoncepção; Esterilização Reprodutiva; Planejamento Familiar

\section{Colaboradores}

E. M. Vieira desenhou o estudo, elaborou os instrumentos, analisou os dados e escreveu o artigo. S. V. Fábio e W. Gueleri colaboraram fornecendo acesso aos dados coletados e elaborando os instrumentos. M. P. Picado e E. Yoshinaga participaram do estudo coletando os dados. L. Souza participou do estudo elaborando a maior parte da análise estatística.

\section{Agradecimentos}

Este estudo foi realizado como um projeto-piloto de parte do estudo Avaliação da Oferta e Satisfação com os Métodos Cirúrgicos de Planejamento Familiar após a Implantação da Lei 9.263 no Município de Ribeirão Preto, financiado pela Fundação de Amparo à Pesquisa do Estado de São Paulo (processo 2003/00549-0). 


\section{Referências}

1. Conselho Regional de Medicina do Estado de São Paulo. Aspectos éticos que envolvem a esterilização. Ética Médica 1988; 1:67.

2. Berquó E, Cavenaghi S. Direitos reprodutivos de mulheres e homens face à nova legislação brasileira sobre esterilização voluntária. Cad Saúde Pública 2003; 19:441-53.

3. Vieira EM, Ford NJ. The provision of female sterilization in São Paulo, Brazil: a study among lowincome women. Soc Sci Med 1995; 42:1427-32.

4. Caetano AJ. Sterilization for votes in the Brazilian Northeast: the case of Pernambuco [PhD Thesis]. Austin: University of Texas; 2000.

5. Vieira EM. A implementação da Lei 9.263/planejamento familiar no Município de Ribeirão Preto: a esterilização feminina. Ribeirão Preto: Departamento de Medicina Social, Faculdade de Medicina de Ribeirão Preto, Universidade de São Paulo; 2001. (Relatório Final de Pesquisa).

6. Minella LS. A produção científica sobre esterilização feminina no Brasil nos anos 80 e início dos anos 90: um debate em aberto. Revista Brasileira de Estudos Populacionais 1998; 15:3-22.

7. Vieira EM. O arrependimento após a esterilização feminina: é possível prevenir? Reprod Clim 1999; 14:178-84.

8. Vieira EM. Arrependimento após a esterilização feminina. Cad Saúde Pública 1997; 14 Suppl 1:5869 .

9. Sociedade Civil Bem-estar Familiar no Brasil/ Macro International. Pesquisa nacional de demografia e saúde/Brasil-1996. Rio de Janeiro: Sociedade Civil Bem-estar Familiar no Brasil; 1997.
10. Vieira EM, Badiani R, Fabbro AL, Rodrigues Jr. AL. Características da contracepção no Estado de São Paulo. Rev Saúde Pública 2002; 36:263-70.

11. Gueleri W, Vieira EM, Porto MCF, Garcia MLB, Chiavenato MT. A implementação da lei de planejamento familiar (9.263) no Município de Ribeirão Preto. Ciênc Saúde Coletiva 2000; 5:44-5.

12. Vieira EM, Gueleri W, Porto MCF, Oliveira MAFC, Garcia MLB, Chiavenato MT. Capacitação profissional para implementação do aconselhamento e orientação em planejamento familiar na rede municipal de saúde de Ribeirão Preto. Ciênc Saúde Coletiva 2000; 5:326.

13. Duarte GA, Alvarenga AT, Osis MJD, Faúndes A, Souza MH. Participação masculina no uso de métodos contraceptivos. Cad Saúde Pública 2003; 19:207-16.

14. Ford NJ, Vieira EM, Vilella WV. Beyond stereotypes of Brazilian male sexuality: qualitative and quantitative findings from São Paulo. Cult Health Sex 2003; 5:53-69.

15. Viveros M, Gómez F, Otero E. Las representacionaes sociales sobre la esterilización masculina. El punto de vista de los orientadores del servicio de vasectomia en la Clínica del Hombre, en Bogotá, Colombia. Cad Saúde Pública 1998; 14 Suppl 1:97-103.

Recebido em 19/Mar/2004

Versão final reapresentada em 16/Mar/2005

Aprovado em 16/Mai/2005 